\title{
Qual o Argumento para a ATItude Ontológica NATURAL?
}

\author{
What is the Argument for the Natural Ontological Attitude? \\ Bruno MaLAVOLta E Silva \\ UFRGS/CNPq, BRASIL \\ malavolta3@gmail.com
}

\begin{abstract}
Arthur Fine presented the Natural Ontological Attitude (NOA) as a third alternative between scientific realism and anti-realism by identifying a core position contained in both and rejecting any philosophical addition to this core. At first, Fine's proposal was understood as offering a doxastic middle ground between believing in the truth of a theory and believing in its empirical adequacy. In this reading, NOA was widely disregarded after Alan Musgrave's criticisms of it, which characterized Fine's proposal as a form of realism. After that, NOA was reinterpreted as a local variety of realism focused in changing the attitude used to settle the scientific realism debate, by rejecting global philosophies with an approach external to science, and by considering only the scientific evidence with a contextualist mood. Although this reading clarifies how to understand NOA, there is still no consensus about what is Fine's argument to support it. I organize the four main interpretations of Fine's defense and point their main flaws. Finally, I develop some clarifications about NOA in order to solve the flaws of the preceding interpretations, defending that NOA is based upon a prevalence of the epistemic values actually used in scientific practice.
\end{abstract}

Keywords: Arthur Fine $\bullet$ natural ontological attitude $\bullet$ naturalism $\bullet$ scientific realism $\bullet$ local realism • stances

\section{Introdução}

"O Realismo está morto", declara Arthur Fine sobre o realismo científico. Sua morte é anunciada por físicos que desenvolvem sua ciência sem aderir ao realismo, e por neopositivistas que aceitam todos os resultados científicos sem sequer precisar considerar questões de realismo como mais do que pseudoquestões. Tentativas de defender o realismo perduram, mas representam o primeiro estágio do luto, o estágio de negação (Cf. Fine 1986a, p.83).

Fine vê o debate sobre realismo científico como estagnado e infértil. Para superar a estagnação desse debate, Fine oferece a Atitude Ontológica Natural como uma alternativa teórica para uma filosofia da ciência progressiva e que não se comprometa com realismo ou anti-realismo (Cf. Fine 1986a, p.84). A NOA (Natural Ontological Attitude $)^{1}$ é constituída por dois elementos assumidos conjuntamente: a posição central; e o anti-essencialismo filosófico. Deixe-me explicá-los. 
Para introduzir à NOA, Fine salienta a existência de um ponto teórico comum, assumido por realistas e anti-realistas científicos, e que assim representa uma posição central do debate, resumida na seguinte tese: é razoável aceitar os resultados confirmados das investigações científicas, no mesmo sentido em que aceitamos nossas crenças perceptivas mais básicas (Cf. Fine 1986a, pp.95-6). Uma vez que a posição central constitui uma interseção entre realismo e anti-realismo, o que distinguirá ambos será a teorização filosófica que cada um adiciona à posição central. Anti-realistas adicionarão uma concepção de verdade (e.g. instrumentalista, pragmatista ou epistêmica); ou alguma restrição metodológica à ciência (e.g. recusa de modelos inferenciais abdutivos); ou alguma imposição dos limites epistêmicos da ciência baseada numa distinção entre observável e inobservável; ou ainda alguma teorização sobre o funcionamento da ciência (e.g. explicação de leis científicas) (Cf. Fine 1986a, p.97). Em contrapartida, realistas adicionarão à posição central um enfático murro na mesa enquanto gritam "Realmente!". Ou seja, assumirão que a aceitação de uma teoria envolve um compromisso com sua verdade, e adicionarão ênfase na afirmação de que proposições científicas são o caso realmente, para salientar que são verdadeiras em um sentido de correspondência com a realidade ao invés de em um sentido antirealista de verdade. Além disso, também adicionarão uma concepção realista sobre o progresso científico (e.g. a ciência progride aproximando-se da verdade) e alguma teorização sobre a confiabilidade da metodologia científica (Cf. Fine 1986a, p.98).

Ao lado da posição central, o segundo elemento constitutivo da NOA é o antiessencialismo filosófico, recorrente na defesa de Fine. O essencialismo é identificado como uma postura metodológica compartilhada por realistas e anti-realistas na medida em que ambas as posições parecem tentar oferecer uma interpretação filosófica da prática científica que revele sua essência, ou que abranja a ciência como um todo. $\mathrm{O}$ anti-essencialismo expressa a atitude de recusar estas interpretações filosóficas da ciência. Assim, após identificar a posição central como um campo pacífico no debate, Fine propõe que se adote somente a posição central sem as adições filosóficas defendidas por nenhum dos dois lados, e a NOA é apresentada como a posição central "ela mesma, e só ela mesma"2 (Fine 1986a, p.97). Assumindo somente a posição central sem adições realistas ou anti-realistas, a NOA permite a adoção uma atitude pró-ciência sem ter de sustentar reconstruções filosóficas da prática científica ou de impor aos cientistas prescrições conceituais e metodológicas. A NOA propõe aceitar a prática científica em seus próprios termos, e com isso nos livra de onerações filosóficas externas a essa prática (Cf. Fine 1986a, p.97; 1991, p.87; 1996, pp.173-88).

Este artigo investiga qual a melhor maneira de compreender e defender a NOA. As seções 2 e 3 introduzem as principais interpretações da posição central que servirá de base para a compreensão da NOA. Na seção 2, apresento as interpretações doxásticas da posição central que buscam situar a NOA como um meio-termo entre as atitudes de crer e descrer que as teorias são (realmente) verdadeiras. Nesta interpretação, a 
NOA enfrenta graves dificuldades. Assim, na sessão 3, avanço para a interpretação da NOA como um realismo local, a qual destaca a atitude anti-essencialista apresentada por Fine. As seções 4 e 5 investigam como estruturar a defesa da NOA. A seção 4 compila as principais interpretações do argumento de Fine na literatura secundária e mostra os limites de cada uma. Por fim, na seção 5, defendo uma reconstrução da defesa de Fine baseada na primazia pelo senso comum, a fim de resolver os problemas das interpretações anteriores.

\section{A posição central e a dimensão doxástica}

Fine introduz a posição central como consistindo em um ponto teórico consensual no debate, capaz de provocar acordo entre realistas e anti-realistas. ${ }^{3}$ Tendo em vista que a NOA é introduzida como a posição central "ela mesma e só ela mesma", compreendê-la será o primeiro passo fundamental para entender a NOA. A primeira caracterização da posição central oferecida por Fine é a seguinte:

[PC1]: "aceitar a evidência de nossos sentidos e, do mesmo modo, aceitar os resultados confirmados da ciência" (grifo original, Fine 1986a, p.95).

Tomada isoladamente, a proposta de PC1 é extremamente vaga. Na sequência, porém, Fine especifica: "O que é aceitar a evidência dos sentidos e, "do mesmo modo", aceitar as teorias científicas confirmadas? É tomar ambas como verdadeiras em nossa vida" (Fine 1986a, p.95). Assim, a posição central que constitui o núcleo da NOA passa a ser melhor expressa por PC2:

[PC2]: "aceitar as teorias científicas confirmadas como verdadeiras em nossa vida" (Fine, 1986a, p.95).

A formulação de PC2 levanta um problema imediato para a formulação da NOA: como compreender PC2 de modo a obter uma posição consensual? (cf. Musgrave 1989). De modo geral, para qualquer definição minimamente plausível de realismo que adotemos (e.g. as teorias científicas maduras constituem conhecimento relevante de entidades inobserváveis), o problema poderá ser agravado assumindo a forma de um dilema: ou PC2 implica a posição realista, e logo não será aceita pelo anti-realista; ou PC2 não implica a posição realista, e logo o realista não a aceitará a posição central "só ela mesma" (o que é uma parte integral da NOA).

Podemos nos questionar mais afundo como Fine pretende compreender PC2 a fim de buscar uma solução para este dilema. Duas noções são centrais aqui: verdade e aceitação. Quanto a noção de verdade, Fine declara adotar uma concepção referencial deflacionista de verdade: 
Quando a NOA nos aconselha a aceitar os resultados da ciência como verdadeiros, considero que devemos tratar a verdade da maneira referencial usual, de modo que uma sentença (ou afirmação) seja verdadeira apenas se as entidades referidas estiverem dispostas nas relações referidas. Assim, a NOA sanciona a semântica referencial ordinária e nos compromete, através da verdade, com a existência dos indivíduos, propriedades, relações, processos e assim por diante referidos pelas afirmações científicas que aceitamos como verdadeiras. (Fine 1986a, p.98).

Fine aceita explicitamente uma teoria referencial da verdade, onde a verdade de uma proposição implica a existência dos indivíduos e propriedades referidos por ela. ${ }^{4}$ Isto aproxima a NOA de uma posição realista que prescreva a verdade de teorias científicas bem confirmadas. Mas Fine distingue-se do realista, explicando que apenas o realista assume uma noção de verdade por correspondência. Neste ponto, Fine critica ao realismo por tentar fomentar uma teoria da verdade que "explique o que torna a verdade verdadeira", que trate a verdade como um tipo natural, ou que tente demonstrar a essência da verdade e o que todas as verdades têm em comum (Cf. Fine 1986a, p.97). Ao invés disso, Fine propõe que a NOA dê um passo atrás nessa busca essencialista, e que ainda que todos estejamos comprometidos com alguma noção de verdade, não temos boa razão para assumir que a verdade tenha alguma essência ou que seja um tipo natural (Fine 1984b, p.56; 1996, pp.187-8).

No entanto, Fine não oferece nenhuma razão sobre porque um realista precisaria se comprometer com essa noção essencialista de correspondência, ao invés de aderir uma noção de verdade referencial e deflacionada como a que ele próprio adota. Uma ideia cardinal ao realista (e repelida pelos anti-realistas) é a de que certas teorias científicas nos oferecem algum conhecimento acerca de entidades inobserváveis. Se assumirmos uma interpretação semântica literal destas teorias pelo seu valor de face (por exemplo, se interpretarmos que teorias de átomos falam literalmente sobre átomos inobserváveis, contrariamente ao que propõem o instrumentalismo ou o verificacionismo semântico), então esta ideia será satisfeita ao aceitarmos as teorias como verdadeiras mesmo no sentido deflacionista. A adoção de uma teoria da verdade deflacionista, portanto, torna PC2 em uma posição caracteristicamente realista, ainda que metafisicamente deflacionada. Nessa linha, Alan Musgrave (sendo um bom realista) assume que o sentido mínimo de correspondência, compreendida como satisfação entre afirmação e referente, já é suficiente para caracterizar uma posição estritamente realista:

Então a NOA é um realista que evita murros na mesa, bateção de pés e gritaria. Enquanto os realistas antigos gritavam e esperneavam em oposição às concepções antirrealistas da verdade, na Arca da NOA os realistas se contêm em uma obstinada recusa de amplificar seu conceito semântico referencial de verdade. Enquanto a Arca da NOA navega ao pôr do sol, ela carrega ape- 
nas realistas educados e contidos. Eu prometo não gritar mais, para que eu possa me juntar a este feliz navio. (Musgrave, p.386).

Para reabilitar a NOA enquanto posição independente, alguns autores propõem que a NOA seja aproximada de uma atitude pragmatista (e.g. Kukla, 1994; Crasnow, 2000). Apesar de o pragmatismo ser um dos "ismos" que Fine rejeita, PC2 sugere que as teorias sejam aceitas como verdadeiras em nossas vidas, o que pode sugerir uma dimensão prática da aceitação. Uma maneira óbvia de distanciar PC2 do realismo e destacar sua dimensão pragmática seria invocar uma teoria da verdade não-referencial (e.g. verdade pragmatista ou epistêmica), mas isto iria gritantemente contra os propósitos anti-essencialistas que Fine estipula para a NOA, além de torná-la em uma posição não-consensual para o realista. Uma proposta alternativa e um pouco mais sofisticada destaca a noção de aceitação, tirando o foco da noção de verdade.

Primeiramente, note-se que a NOA adere a uma concepção de ciência onde os cientistas aceitam (e rejeitam) teorias e hipóteses, diferentemente, por exemplo, do bayesianismo radical de Richard Jeffrey (1992) onde cientistas atribuem somente probabilidades às teorias. Em segundo, tipicamente a noção de 'aceitação científica' recebe interpretações distintas por parte do realista e do anti-realista. Uma noção realista de aceitação inclui algum compromisso ontológico relacionado a verdade da teoria. Uma noção anti-realista típica compreende a aceitação de uma teoria em termos pragmáticos, como indicando uma disposição para utilizar aquela teoria e para endossar seu programa de pesquisa. Essa disposição prática virá acompanhada de alguma crença otimista quanto ao potencial preditivo da teoria, tal como a crença de que a teoria é um instrumento de predição confiável (no caso do instrumentalismo), ou como a crença de que a teoria é empiricamente adequada (no caso do empirismo construtivo).

Fine sugere que a noção científica de aceitação envolva um certo compromisso prático para agir a partir da teoria e para incorporá-la em nossas vidas. Mas para além disso, a questão interpretativa acerca das implicações ontológicas de aceitar uma teoria é uma questão que a ciência (no mais das vezes) pode deixar em aberto sem ser prejudicada em seu desenvolvimento (1996, pp.187-8). ${ }^{5}$ Além disso, mesmo que certos contextos científicos específicos exijam (de modo não circular) uma noção de aceitação realista ou anti-realista, isto não deve nos iludir em pensar que esta mesma noção de aceitação precise ser generalizada para toda a prática científica. Focando-se apenas nesta dimensão prática da aceitação de teorias, Fine parece conseguir capturar um ponto comum entre realistas e anti-realistas, na medida em que ambos endossam ao desenvolvimento da prática científica.

O problema é que, nesta interpretação baseada no aspecto prático da aceitação científica, voltamos a cair no lado anti-realista do dilema. Pois, se a aceitação pragmática for completamente neutra (ou proibitiva) a respeito da verdade referencial 
das teorias, então se tornará uma forma agnóstica de anti-realismo, onde não estamos justificados a afirmar nem a verdade nem a falsidade das teorias científicas. A formulação pragmática da NOA apenas evita a apresentação explícita de uma postura doxástica para com as teorias, mas nessa medida ela é incapaz de oferecer um meio-termo entre realismo e anti-realismo, pois a mera recusa de recomendações doxásticas (para com as teorias) já é uma forma tradicional de anti-realismo. O fato de a interpretação pragmática da posição central tornar a NOA em um anti-realismo por si só não elimina sua viabilidade filosófica, mas é suficiente para situar a NOA em um contexto tradicional do debate, retirando seu caráter de terceira alternativa e comprometendo-a com os mesmos ônus teóricos do anti-realismo.

Dada a pretensão inicial de introduzir a NOA como uma terceira alternativa entre realismo e anti-realismo, a proposta de Fine parece falhar consideravelmente. De um lado, podemos tentar compreender a NOA de modo focado na aceitação prática das teorias descomprometida com sua verdade referencial (o que Fine não faz), mas isso geraria uma posição anti-realista agnóstica. De outro lado, podemos atribuir à posição central a aceitação de uma teoria deflacionista da verdade, mas isso a tornaria em uma posição caracteristicamente realista. Fine inicia seu artigo "The Natural Ontological Attitude" proclamando a morte do realismo, mas os realistas julgam a NOA bastante alinhada a suas visões. Musgrave retrata que "a NOA é uma posição inteiramente realista: na arca de NOA, o realista pode alegremente navegar sobre o dilúvio de críticas" (Musgrave 1989, p.383). Com isso, a argumentação de Fine fica bem resumida no comentário de Laudan: "O realismo está morto; vida longa ao realismo!" (apud. Leplin 1997, p.140).

Até aqui, argumentei em favor de duas conclusões. Primeiro, endossei a crítica de Musgrave de que não há uma maneira razoável de compreender a NOA como um meio-termo doxástico entre realismo e anti-realismo. Segundo, de um ponto de vista exegético, espero ter dado alguma plausibilidade à ideia de que a posição efetivamente defendida por Fine é uma posição caracteristicamente realista devido ao seu compromisso com a verdade referencial. No entanto, a proposta de interpretar a NOA como um realismo pode ser extremamente contra-intuitiva, dado que Fine não só rejeita explicitamente ao realismo, como ainda faz a alegação contundente de que "o realismo está morto". Para compreender como Fine poderia fazer tais rejeições mesmo adotando uma posição realista, é preciso atentar para dois pontos.

Primeiro, relembre-se que Fine justifica sua afirmação de que "o realismo está morto" apontando que físicos não assumem uma postura realista com a ontologia de suas teorias. Assim, podemos entender que a NOA só implica a rejeição do realismo na medida em que ele for rejeitado pelos cientistas. Mas mesmo se concedermos que isto ocorra na física quântica e na teoria da relatividade (foco principal de Fine), não temos qualquer base para afirmar que cientistas não creem na ontologia de outras teorias mais disseminadas (e.g. mitocôndrias, genes, tabela periódica). Nesta medida, 
a afirmação desqualificada de que o realismo está morto constituiria uma generalização apressada e contrária à própria NOA na defesa de Fine, exceto se caridosamente lida como uma afirmação contextual às teorias da física de ponta.

Segundo, o fato de Fine rejeitar repetidamente ao realismo pode ser explicado por sua compreensão metafisicamente inflada da posição realista. O realismo costuma ser associado a alguma cláusula de que o mundo e seus objetos são independentes de nós. Para Fine, o realismo trata de algo "lá fora, externo, e (em geral) independente de nós [... ] o que eu chamarei de o Mundo" (1986b, p.150). Fine rejeita este realismo pois para ele não teríamos como acessar epistemicamente ao Mundo. Este problema de acesso é erguido da seguinte forma:

(i) o que quer que nós observemos, ou, de modo mais geral, o que quer que nos interajamos causalmente com, certamente não é independente de nós. Este é o problema da reciprocidade (Fine 1986b, p.151), e

(ii) qualquer informação que nos retiremos de tal interação é, prima facie, informação de coisas interagidas-com. Esse é o problema da contaminação (Fine 1986b, p.151).

O problema então se sustenta na ideia de que, diante da contaminação e da reciprocidade causal, não teríamos como acessar ao Mundo independente, mas apenas ao mundo contaminado de nossa experiência. Não podemos sair de nossa experiência e acessar a uma área externa, ou a um ponto de vista divino, para verificar a correspondência entre nossas representações e o Mundo. O mundo que conhecemos, portanto, não é o Mundo independente de coisas em si isoladas de nós, mas um mundo cotidiano de objetos contaminados por nossa interação e experiência.

Creio que este ataque mostre que a concepção de realismo a que Fine se opõe é consideravelmente distinta do realismo de senso comum que boa parte (senão a maioria) dos realistas atualmente defenderia (e.g. Niiniluoto 2002 Cap. 2; Sankey 2001). A ideia simples de um realismo de senso comum é a de que os objetos do mundo podem existir (e existem) independente de nossa percepção e interação causal. Assim, mesas e cadeiras continuam existindo quando saímos da sala. É tautológico que, necessariamente, só podemos interagir causalmente com coisas interagidas-com. Mas disso não se segue que as coisas com que interagimos sejam necessariamente-interagidas-com, ou seja, que elas não possam existir a parte dessa interação. Assim, o realismo não depende de uma perspectiva divina que nos permita acessar ao mundo independente. E enquanto Fine recusa um realismo de coisas em si isoladas de qualquer interação, boa parte dos realistas está mais interessada em um realismo de senso comum. É este mesmo realismo de senso comum, proponho, que está contido na NOA. 


\section{Realismo local e anti-essencialismo filosófico}

Tendo visto a interpretação proto-realista e a interpretação pragmática da posição central (e consequentemente, da NOA), vimos que a NOA flutua entre realismo e anti-realismo sem de fato apresentar uma terceira alternativa consensual ao debate. Diante deste diagnóstico, não há interpretação da NOA que apresente um meio-termo entre acreditar ou não nas teorias científicas, entre realismo e anti-realismo compreendidos de modo doxástico. Uma leitura alternativa propõe a NOA deixe de ser vista como uma terceira alternativa doxástica em relação a crer nas teorias científicas, e passe a ser entendida como uma mudança de atitude a respeito de como justificamos nossa crença nas teorias científicas: a crença em uma teoria não poderá estar baseada em teorias filosóficas externas à ciência, mas somente na apresentação da própria evidência científica. Nesse sentido, a atitude ontológica natural consiste na atitude que cientistas exercem ao defender ou criticar teorias científicas, e seu adepto defenderá sempre a ontologia assumida pelos próprios cientistas, ou assumirá o ônus de se posicionar como um cientista (cf. Abela 1990; Pihlström 1996; Alspector-Kelly 2003; Ginev 2012; e Wolff 2019). Essa postura afeta a discussão sobre realismo na medida em que pretende rejeitar interpretações filosóficas globais da ciência, ainda que de modo local o defensor da NOA seja um realista ou um antirrealista, dependendo da evidência científica. Assim, temos a seguinte reformulação da posição central:

[PC3] Posição Central: Devemos aceitar os resultados científicos de modo local.

Essa proposta é bem expressa pela distinção entre um realismo "de andar de baixo" ("downstairs") e um realismo de andar de cima ("upstairs"), proposta por Alspector-Kelly (2003, pp.317-20). A argumentação tradicional do debate realista parece assumir uma distinção entre o contexto científico, onde se discute a aceitação de uma teoria através de evidências e hipóteses científicas, e um contexto filosófico onde se critica ou avalia as atividades do contexto científico. Assim, anti-realistas como Van Fraassen não pretendem questionar a escolha ou a aceitação de teorias dentro da prática científica, mas sim questionar se a aceitação científica de uma teoria é uma boa justificação filosófica para aceitar sua verdade. O debate portanto passa a possuir dois níveis: no andar de baixo, a discussão ocorre imersa na prática científica; no andar de cima, a discussão assume um distanciamento crítico e se propõe a julgar filosoficamente a prática científica do primeiro andar.

Esta distinção abre duas possibilidades estratégicas para o realismo. Uma opção é a de aceitar a distinção entre o contexto de imersão científica e o contexto de autonomia filosófica, e tentar disputar com o anti-realista no andar de cima. Isto constituiria o realismo do andar de cima. Outra opção é a de atacar a distinção entre os contextos. Se a distinção for inteiramente rejeitada como ininteligível, argumentos filosóficos que busquem criticar os resultados da prática científica poderão ser 
criticados e rejeitados como cientificamente ruins. Ou ainda, pode-se aceitar a inteligibilidade da distinção, mas criticar a validade normativa de argumentos do andar de cima. Esta estratégia constitui o realismo do andar de baixo, que se recusa a subir para o segundo nível. Aqui situamos a NOA.

Destaque-se que a formulação inicial da posição central é definida pelo modo com que aceitamos a evidência científica: "aceitar os resultados da ciência do mesmo modo com que aceitamos evidência dos sentidos" (Fine 1986a, p.95). A formulação de (PC3) busca enfatizar esse aspecto da NOA como um modo de se engajar epistemicamente. Fine concede que esse modo de aceitar uma teoria possa ser interpretado de modo realista, como implicando um compromisso com a verdade da teoria (Fine 1986a, p.95; 1996, pp.187-8). Mas o que caracteriza a NOA não está estritamente na questão de crer ou não nas teorias. A atitude de aceitação da evidência científica pode conduzir tanto a uma crença realista quanto anti-realista: "A NOA é uma atitude fundamentalmente heurística, compatível com diferentes avaliações de investigações científicas particulares" (Fine 1984b, p.63). O que define a NOA é, acima de tudo, o modo como decidimos se aceitamos ou rejeitamos uma teoria. Mais especificamente: "A atitude que marca a NOA é simplesmente esta: tente compreender a ciência em seus próprios termos, e tente não impor interpretações à ciência" (Fine 1984b, p.62).

Um aspecto crucial da apresentação de Fine é sua caracterização da NOA como uma atitude: "A NOA é uma atitude, em oposição a um "ismo" ou a um programa filosófico. É uma postura que podemos adotar, um modo de começar a pensar sobre um problema ou de procurar por um" (Fine 1986b; cf. também 1996, pp.172-88). Dado o teor filosoficamente minimalista com que Fine apresenta a NOA, a intenção aqui claramente não é a de forjar uma distinção exclusiva e categórica entre atitudes e teorias. Ainda assim, explicar a noção de atitude é esclarecedor para a proposta da NOA. Embora a literatura ainda não tenha obtido um consenso sobre a natureza exata de uma atitude (stance), é de praxe assumir que a adoção de uma atitude teórica envolve certas crenças proposicionais, embora não se resuma a isto. Pessoas com as mesmas crenças acerca de um problema teórico podem escolher adotar diferentes atitudes em sua resolução, como uma abordagem mais agressiva e arriscada, ou uma abordagem mais paciente e cautelosa. Uma definição mais precisa é encontrada em Rowbottom e Bueno (2011a; 2011b), a qual caracteriza uma atitude em três elementos: (a) um modo particular de engajamento, (b) um estilo de raciocínio, e (c) certas atitudes proposicionais. Assim, a NOA consiste em uma atitude na medida em que propõe um modo particular de se engajar e raciocinar sobre questões de filosofia da ciência, a saber, começando por tratá-las internamente à ciência, usando os valores cognitivos e os estilos de raciocínio científicos, e recusando tratamentos filosóficos externos a ciência. Se não estamos dispostos a tratar uma questão de modo interno à ciência, isto é, como um(a) cientista faria, então devemos respeitar e confiar nas decisões da comunidade científica que o fez. 
A formulação de PC3 pode sugerir que se pressupõe certo consenso dentro dos resultados científicos. Isto levanta a questão de o que a NOA prescreveria em um domínio cujos resultados são disputados dentro da comunidade científica (por exemplo, em discussões atuais sobre a interpretação da mecânica quântica). Nestes casos, vejo duas opções, dependendo de em que contexto estivermos. Primeiro, a recomendação primária da NOA é a de que tratemos a questão do mesmo modo que os cientistas. Assim, para decidir qual interpretação aceitar, teríamos de fazer o trabalho duro de compreender a discussão técnica pertinente e então nos posicionarmos como um especialista (isto não implica que só haja uma maneira de se posicionar como um especialista, dado que existem divergências metodológicas e teóricas entre especialistas, mas implica haver uma diferença relevante entre fazê-lo e não fazê-lo). Se, no entanto, não dominamos tal discussão técnica e não estamos na posição de um especialista, então a recomendação da NOA é respeitar a autonomia da comunidade científica (cf. Fine 1996, pp.175-7). Isto significa aceitar que a questão é tão incerta quanto faltar consenso, e não tentar decidi-la de modo externo à ciência.

Por fim, precisamos atentar para o outro lado da NOA. A NOA é constituída pela posição central ela mesma e só ela mesma. Assim, junto com a aceitação de resultados científicos locais, teremos uma rejeição quaisquer resultados externos à ciência:

[AE] Anti-Essencialismo: Devemos aceitar somente os resultados científicos obtidos de modo local.

Este aspecto anti-essencialista é o que confere o caráter programático da NOA para reformular o modo com que o debate é conduzido. Nesta formulação, a defesa e a apresentação da NOA se baseiam na distinção entre a abordagem local ou interna à ciência, e a abordagem filosófica global ou externa à ciência, na avaliação de teorias científicas. Essa distinção não precisa ser compreendida de modo categórico e bem delimitado, podendo ser compreendida como uma distinção de grau. Por exemplo, a questão de qual a finalidade de um empreendimento científico pode ser abordada com diferentes graus de escopo, e a preferência por uma abordagem local sugere que o escopo correto seja definido a partir da perspectiva do próprio empreendimento científico analisado (cf. Fine, 1996, p.181). Com essa distinção, afirma-se que somente evidências provindas da abordagem local possuem prioridade normativa.

A partir de então, para compreender a relevância da NOA, é importante analisar como ela impacta nos argumentos e nas posições tradicionais do debate. De modo geral, Fine apresenta o realismo e anti-realismo tradicionais como posições globais no sentido de oferecer uma visão axiológica da ciência como um todo (por exemplo, como uma perspectiva axiológica de compreender a ciência como empreendimento unitário movido pelo mesmo fim: a busca pela verdade, ou a adequação empírica) (Cf. Fine 1984b, p.83). Filosofias globais, nestes termos, serão rejeitadas por Fine por 
serem instâncias de filosofias do andar de cima. ${ }^{6}$ Fine enfatiza a falácia de inferir "todos os cientistas tem um mesmo fim" de "todos os cientistas tem um fim". Também rejeita as tentativas realistas e anti-realistas de oferecer princípios epistemológicos que interpretem a história da ciência e o processo de aceitação de teorias como um todo (cf. Fine 1991, p.93; 1984b, pp.61-2; e 1986a, pp.98-9), incluindo as tentativas de realismos seletivos que restringem (de maneira algorítmica) o escopo de aplicação de seus princípios (cf. Fine 1991). Ao invés, a NOA assume que não há princípio epistêmico que governe a ciência como um todo, e que questões de axiologia só ocorrem legitimamente de modo contextualizado e específico: "Para que propósito um instrumento específico está sendo usado? [... ] Que objetivos relevantes seriam alcançados com a construção de aceleradores capazes de gerar níveis de energia transpondo $10^{4} \mathrm{GeV}$ ? [... ] Etc" (1984b, p.61; cf. também 1986a, p.101). Paralelamente, a NOA permite que a prática científica utilize noções tipicamente filosóficas (verdade, justificação, explicação, razão, etc), mas de modo local, governado pelas necessidades específicas aos cientistas de um contexto particular, e não a partir de uma definição filosófica generalizada e imposta aos cientistas (cf. 1996, pp.175-9).

A NOA também implica no tratamento da ciência como epistemicamente autônoma e na rejeição de qualquer fundamentação filosófica da ciência. O ponto aqui não contrapõe somente à imagem positivista tradicional que oferece uma filosofia para fundamentar infalivelmente a ciência, mas busca principalmente contrapor a NOA a um modus operandi usado nas defesas realistas e anti-realistas recentes. Para Fine, um ponto comum entre realistas e anti-realistas é sua tentativa de defender uma interpretação filosófica da ciência (que inclua uma axiologia da ciência, princípios epistêmicos e metafísicos) através do apelo explicativo dessa interpretação. Isto parece pressupor que sejamos racionalmente obrigados a escolher entre a melhor interpretação filosófica da ciência dentre as alternativas no páreo. Fine rejeita que a ciência precise de uma interpretação externa, e se recusa a entrar nesta briga: "a ciência não é carente nesse sentido" (Fine 1984b, p.61; Cf. também 1996, p.174).

Resta considerar a relação entre a NOA e os argumentos tradicionais do debate. Alguns realistas distinguem entre uma interpretação geral do argumento do milagre, onde o sucesso da ciência considerado como um todo seja evidência para fortalecer a crença na confiabilidade dos métodos científicos, e uma interpretação a varejo onde o argumento do milagre passa a ser um modelo meramente descritivo das inferências particulares realizadas por cientistas em prol da verdade de teorias (por exemplo, Psillos 1999; Magnus e Callender 2002). Nesse caso, o argumento tem apenas a pretensão de apresentar a evidência científica existente em favor da verdade de uma teoria. Esta versão a varejo do argumento do milagre sustenta uma defesa local do realismo científico perfeitamente condizente com a NOA. No entanto, as formulações estatísticas do argumento seriam rejeitadas, dado seu caráter global e extra-científico. Para além da própria evidência científica em favor de uma teoria, não há generali- 
zação filosófica capaz de reforçar normativamente a crença realista nas teorias, e muito menos de impor uma crença realista numa teoria cujos próprios proponentes são anti-realistas. Isso desqualifica a pretensão crítica contida em defesas tradicionais do realismo (E.g. Psillos 1999; Leplin 1997; Niiniluoto 2002). Similarmente, a defesa do empirismo construtivo baseada em predileções empiristas ou na economia teórica de uma interpretação anti-realista da ciência (E.g. Van Fraassen 1980; Bueno 1999) seriam inócuas para afetar a crença ou descrença nas teorias, tal como as tentativas de induções pessimistas e filosóficas que buscam questionar a verdade de teorias a partir do fracasso de outras teorias (Laudan 1984; Stanford 2006). Wolff resume com precisão: "Um experimento particular pode ser tratado como confirmando ou desconfirmando uma certa hipótese, mas não como confirmando ou desconfirmando a Ciência" (2019, p.492).

\section{Defesas da NOA}

Até aqui, foquei-me em analisar no que consiste a NOA, esclarecendo o conteúdo da posição central e usando-a para delimitar o escopo da postura anti-essencialista. Tendo compreendido a NOA, resta perguntar que razões temos para assumi-la. No artigo canônico em que Fine introduz a NOA (1986a), sua defesa é centralizada em dois momentos argumentativos: primeiro, Fine introduz a posição central como uma platitude no debate, o que sugere que ela não necessite de uma defesa ulterior; segundo, propõe a NOA como a alternativa teórica de assumir a posição central e somente ela, dispensando adições filosóficas (Fine 1986a, pp.96-7). Nestes termos iniciais, a argumentação de Fine se constrói na seguinte estrutura:

[PC3] Posição Central: Devemos aceitar os resultados científicos de modo local.

[AE] Anti-Essencialismo: Devemos aceitar somente os resultados científicos obtidos de modo local.

$\therefore$ [NOA]: Devemos aceitar um resultado teórico científico se e somente se ele é justificado localmente pela ciência.

Comecemos analisando o suporte de (PC3). Nestes termos, a posição central expressa a atitude pró-ciência da NOA de aceitar a relevância epistêmica da evidência científica. Sua introdução é reforçada pela "postura cotidiana" ("homely line"), que prescreve que tratemos a evidência científica do mesmo modo com que tratamos a evidência de senso comum:

(PC3a) Postura Cotidiana: Devemos tratar a evidência científica do mesmo modo com que tratamos a evidência de senso comum. 
(PC3b) O senso comum prescreve que é razoável aceitar a evidência local para crer ou descrer numa hipótese.

$\therefore$ (PC3) Posição Central: Devemos aceitar os resultados científicos de modo local.

Embora "o modo como tratamos a evidência de senso comum" seja uma expressão extremamente vaga e imprecisa, acredito que seja suficientemente claro como interpretá-la de modo condizente com a defesa de Fine: em nossa prática epistêmica ordinária (a qual Fine se refere como "verdades cotidianas") assumimos certos cânones do que conta como boa e como má evidência para uma hipótese, e é com base nestes mesmos cânones que deveremos avaliar as teorias científicas e os cânones da metodologia científica. A defesa de Fine também se aproxima da ideia de uma continuidade entre a metodologia científica e o senso comum, na medida em que a metodologia científica parte dos valores epistêmicos canonicamente assumidos pelo senso comum e os aperfeiçoe ao longo de seu desenvolvimento (Fine 1996, p.174). A distinção entre abordagens locais e globais aqui pode ser compreendida, portanto, como a diferença entre defender uma teoria científica apresentando evidências conforme a estes cânones, ao invés de com base em uma teoria filosófica que pressuponha valores epistêmicos externos à ciência e ao senso comum.

Embora (PC3) constitua o elemento menos problemático da NOA, ainda não passa incontestada. A questão é de se de fato essa é uma posição consensualmente assumida no debate, sem necessidade de justificação ulterior. Dado o teor empírico da defesa tradicional do realismo, muito dificilmente realistas rejeitarão esta posição central. Mas a situação não é pacífica diante do anti-realismo.

Em primeiro, temos as estratégias anti-realistas baseadas na história da ciência, tal como a indução pessimista (Laudan 1984) ou a indução de alternativas não concebidas (Stanford 2006), que podem ser lidas como atacando diretamente o valor normativo da evidência científica através de evidência (histórica) de segunda ordem. Em segundo, temos as estratégias anti-realistas baseadas em atitudes empiristas que rejeitam a valor epistêmico de virtudes teóricas extra-empíricas (Van Fraassen 1980, 2002; Bueno 1999). Em ambos os casos, anti-realistas podem aceitar tanto a racionalidade da escolha de uma teoria por parte dos cientistas quanto a relevância de certas virtudes teóricas (simplicidade, poder explicativo, etc) como valores metodológicos capazes de justificar estas escolhas. Assim, anti-realistas estarão em pleno acordo com a NOA no que diz respeito à descrição da prática científica, ao desenvolvimento da ciência, e a quais teorias devem ser escolhidas e desenvolvidas. No entanto, antirealistas rejeitarão a posição central e a NOA na medida em que prescrevem uma interpretação filosófica realista das virtudes teóricas e dos cânones metodológicos da ciência, buscando substituí-las por uma interpretação anti-realista e exclusivamente pragmática. Isto é, em casos onde cientistas utilizam virtudes teóricas não apenas como critérios normativos para a escolha de teorias, mas também como critérios 
epistêmicos para crer numa teoria (dando uma interpretação realista a estas virtudes teóricas), anti-realistas defenderão que estas virtudes sejam relevantes para a escolha de uma teoria e para a crença em sua adequação empírica, mas não para sua verdade (e logo, não para crermos na teoria). Na posição central, devemos sempre aceitar a interpretação filosófica que os cientistas atribuem às virtudes teóricas, pois esta constitui uma parte integral da atividade científica. Na perspectiva anti-realista, devemos rejeitar a interpretação realista das virtudes teóricas mesmo em domínios onde elas são predominantemente usadas pelos cientistas, pois constituem uma extrapolação filosófica dos cientistas e não uma parte integral da ciência, uma vez que não interferem no processo de escolha e de desenvolvimento de teorias (Cf. Van Fraassen 1994).

Na medida em que o senso comum prescreve que é razoável aceitar a evidência de primeira ordem para crer em uma hipótese sobre inobserváveis (conforme PC3b), anti-realistas rejeitarão que devemos tratar a evidência científica do mesmo modo que tratamos a evidência de senso comum (conforme PC3a), sustentando que esta atitude do senso comum deva ser revisada ao invés de estendida à prática científica. Nestes termos, a posição central não será consensual isenta de justificação ulterior. Este é um problema grave, pois se não há justificação para a posição central, também não há para a NOA.

Este constitui o maior problema para a interpretação da NOA como um realismo local, assumida aqui e na seção anterior. Retornarei a este problema na próxima sessão, ao desenvolver o que considero a melhor leitura da NOA, mas por ora o deixemos em aberto e passemos para a avaliação de (AE).

A premissa anti-essencialista (AE) desempenha o papel de rejeitar abordagens globais e imposições filosóficas que restrinjam a atitude local da posição central. Sem $(\mathrm{AE})$, realistas tentarão utilizar abordagens globais para reforçar e incrementar a defesa dos resultados científicos, e anti-realistas invocarão princípios empiristas para revisar a posição central. Assim, (AE) é a premissa crucial para evitar as posições filosóficas tradicionais do debate e distingui-las da NOA, e todo o caráter programático da NOA para reestruturar o debate realista deriva de (AE). Entretanto, não há qualquer consenso sobre quais sejam as razões de Fine para assumir (AE): alguns autores sugerem que (AE) seja uma premissa assumida por Fine sem defensa ulterior, e que por isso o que falte na NOA seja uma defesa de que "menos é mais" é um princípio aplicável no nível metafilosófico (Abela 1996); outros sugerem que a dispensa razoável de abordagens filosóficas globais derive da irrelevância prática dessas abordagens para o desenvolvimento da ciência (Rouse 1988); ou ainda, que o minimalismo filosófico da NOA derive simplesmente da inexistência de uma abordagem filosófica satisfatória que nos convença a sair deste minimalismo (Rouse 1988; Kukla 1994). Na sequência, analiso as quatro principais interpretações de qual seja a defesa de Fine para (AE). 
Como um esclarecimento preliminar, atente-se que a postura anti-essencialista (AE) de Fine pode ser compreendida de dois modos. Seguindo uma interpretação minimalista, (AE) afirmaria que dadas as alternativas filosóficas atualmente disponíveis como interpretações da ciência, nenhuma é uma satisfatória, e por isso não devemos aceitar nada além dos resultados locais da ciência. Nesse caso, a atitude anti-essencialista não constitui uma restrição normativa capaz de neutralizar filosofias, mas sim uma mera constatação da ausência de filosofias legítimas ao nosso alcance. Numa segunda leitura, a interpretação quietista sugere que não apenas não temos uma interpretação filosófica satisfatória da ciência, como também que, em algum sentido, não podemos ter uma tal interpretação. E embora essa afirmação não seja tomada como infalível e irrevisável, é considerada como suficientemente plausível para neutralizar a normatividade de abordagens filosóficas externas a ciência desde seu berço. Ainda que modalmente mais forte, esta interpretação parece mais condizente com o caráter programático da NOA de mudar o modo como o debate é conduzido, e não apenas de rejeitar as alternativas oferecidas. A diferença principal pode também ser apreciada pelo seguinte dilema: a NOA é uma conclusão derivada do fato de que não há posição filosófica satisfatória no debate, ou a NOA é uma premissa pela qual concluímos que realismo e anti-realismo são em princípio insatisfatórios devido a sua abordagem caracteristicamente filosófica? Das quatro interpretações a seguir, as três primeiras estimulam a leitura quietista da NOA, enquanto a quarta enseja a linha minimalista.

\subsection{Leitura quietista por parcimônia}

Numa primeira leitura, a defesa da NOA (especialmente de (AE)) é baseada numa preferência pela simplicidade ou economia teórica. Endossa-se a estratégia de primeiro salientar a existência da posição central como ponto comum no debate, para então defender que se assuma somente a posição central, uma vez que isso permite a adoção de uma postura filosófica pró-ciência livre de excessos filosóficos. Nesse caso, a maior eficiência da NOA, em termos de economia teórica, é o que a torna mais atraente do que as alternativas teóricas do debate: "talvez a maior virtude da NOA seja chamar a atenção para o quão mínima uma filosofia da ciência adequada consegue ser" (Fine 1986, p.97).

Lida deste modo, se a estratégia de Fine parecer minimamente plausível, será somente devido à vagueza e imprecisão com que é apresentada. Uma defesa clara da NOA baseada em sua simplicidade teórica deveria indicar (i) em que sentido de simplicidade teórica a NOA é mais econômica ou minimalista; e (ii) porque aceitar que esse sentido de simplicidade seja relevante de modo a tornar a NOA preferível. O fato de que Fine identifica a posição central como compartilhada por realismo e antirealismo sugere que sua adoção seja dada em termos de força lógica, tal que: uma 
teoria $T_{1}$ é mais simples que $T_{2}$ se $T_{1}$ está logicamente contida em $T_{2}$ (i.e. $T_{2}$ implica $T_{1}$, mas $T_{1}$ não implica $T_{2}$ ). Nestes termos, (i) se sustentaria na medida em que realismo e anti-realismo implicam a posição central, mas não o contrário. Entretanto, nesse caso (ii) se torna extremamente questionável. Economia em termos de força lógica pode ser preferível em casos onde $T_{1}$ e $T_{2}$ estão baseadas na mesma evidência, uma vez que nesses casos a suficiência de $T_{1}$ em lidar com a evidência mostra a falta de evidência para as hipóteses adicionais que $T_{2}$ possui em relação à $T_{1}$. Mas as abordagens filosóficas globais, criticadas por Fine, surgem justamente para lidar com uma evidência de segunda ordem não considerada na prática científica local. É o caso, por exemplo, de análises de casos e evidência histórica invocadas pelas induções pessimistas anti-realistas, ou pela formulação estatística do argumento do milagre. A partir de então, afirmar sem mais que o anti-essencialismo de (AE) deve ser preferido por mera economia teórica parece equivalente a dizer que devemos abandonar todas as vantagens teóricas e filosóficas que uma interpretação da ciência oferece simplesmente para nos comprometermos com menos filosofia. Nesta mesma direção, Abela afirma que o que falta à NOA é "um argumento que afirme o valor de 'menos é mais' no domínio de atitudes [filosóficas]", i.e. o domínio sobre se devemos ou não tentar interpretar filosoficamente a ciência (Abela 1996, p.75).

\subsection{Leitura quietista por pragmatismo}

Uma segunda leitura propõe uma defesa pragmatista (em certo sentido) da argumentação de Fine. Nesse caso, a atratividade da NOA está no fato de que a posição central provê todo o aparato teórico relevante para o desenvolvimento da ciência. Uma vez que a introdução da posição central revela a filosofia realmente relevante para a condução da atividade científica, qualquer filosofia adicional passa a ser vista como desnecessária e dispensável, como um injustificado "comprometimento extracientífico com uma escola filosófica" (Rouse 1986, p.171).

Nesta direção, abordagens filosóficas serão aceitas como normativamente legítimas dentro de um domínio quando contribuírem para o desenvolvimento de um programa de pesquisa sobre esse domínio. Em contraste, abordagens globais serão rejeitadas devido a sua falta de diálogo e relevância para com o empreendimento científico. Repare-se que não se advoga estritamente em prol do quietismo filosófico, uma vez que abordagens filosóficas podem no futuro se mostrar relevantes para a ciência, e com isso ganhar legitimidade; ao invés, trata-se apenas de introduzir um critério de confirmação para decidir a aceitação do valor normativo de abordagens filosóficas, a saber, a contribuição relevante dessa abordagem para um programa de pesquisa científico bem sucedido. O argumento para a NOA, a partir de então, consiste no reconhecimento de que realismo e anti-realismo enquanto filosofias globais da ciência não possuem um histórico de contribuições para a ciência (ainda que o 
possam ter feito enquanto abordagens locais, e logo justificar uma postura realista ou anti-realista em contextos específicos).

Embora possa ser razoável argumentar em favor de uma teoria filosófica a partir da contribuição dessa teoria para o desenvolvimento de uma teoria científica bem sucedida (caso no qual a confirmação da teoria científica poderia servir de confirmação indireta para a teoria filosófica), é mais problemático afirmar que a única via de confirmação para uma teoria filosófica seja sua inclusão na ciência, e sem isso (AE) não se sustenta de maneira clara. Assim, a reação natural a uma defesa pragmatista da NOA é a de questionar porque devamos crer somente no necessário para desenvolver a ciência, uma vez que abordagens filosóficas globais à ciência tipicamente serão defendidas por outros tipos de evidência (e.g. análises de casos, plausibilidade e intuições prima facie, valor explicativo). Se se pretende usar este critério de inclusão cientificista como capaz de neutralizar abordagens filosóficas extra-científicas, então torna-se necessário um argumento mais robusto para a inocuidade de outros tipos de evidência filosófica. Sem isso, a NOA se tornaria em mero cientificismo dogmático.

\subsection{Interpretação quietista por meta-quietismo}

Uma terceira linha interpretativa propõe que a NOA não precise de uma justificação para (AE), uma vez que a atratividade da NOA advém justamente de seu caráter anti-essencialista. Vimos que uma crítica à NOA é a constatação de que falta na defesa de Fine "um argumento que afirme o valor de 'menos é mais' no domínio de atitudes [filosóficas]" (Abela 1996, p.75). Em resposta, Brandom replica que o tipo de argumento exigido por Abela origina justamente o gênero de discussão filosófica que a NOA busca silenciar: "Levantar questões que demandam uma resposta realista ou instrumentalista revela uma doença da qual a NOA quer nos curar" (Brandom 1997, p.233). Para Brandom, o quietismo da NOA se aplica não apenas para dissipar discussões sobre qual a melhor interpretação filosófica da ciência, como também se aplica em discussões meta-filosóficas sobre como decidir qual a melhor interpretação filosófica da ciência.

Inicialmente, não vejo como a NOA poderia razoavelmente silenciar sua própria discussão. Primeiramente, deve estar claro que este meta-quietismo não condiz com a abordagem minimalista, uma vez que a abordagem minimalista por definição deriva (AE) da constatação factual de que não há alternativas filosóficas satisfatórias que complementem ou revisem a posição central, e logo assume o ônus de mostrar como insatisfatórias quaisquer filosofias da ciência de caráter global. A abordagem meta-quietista não assume esse ônus, nem qualquer outro ônus justificatório senão o interno à própria prática científica.

A partir de então, é difícil ver como a postura meta-quietista não seria arbitrariamente dogmática, porquanto não introduz qualquer razão para desqualificar abor- 
dagens globais e extra-científicas. Uma vez que se distinga o aspecto pró-ciência e a postura anti-essencialista da NOA (PC3 e AE), não basta apontar que a aceitação dos resultados científicos não requer um fundamento filosófico (conforme PC3) para sustentar que a ciência não possa ser razoavelmente complementada ou revisada por filosofias externas a ela (conforme $\mathrm{AE}$ ). Anti-fundacionismo não implica quietismo (ao menos não sozinho): há espaço conceitual para uma filosofia da ciência crítica e que respeite a autonomia epistêmica da ciência.

Além disso, a situação não é resolvida pela caracterização da NOA como uma mera atitude. Fine introduz esta caracterização para distanciar a NOA das abordagens filosóficas tradicionais, e alguns autores utilizam esta ideia para inflar o caráter prático da NOA, propondo o abandono de pretensões teóricas normativas para focarse somente em questões de ação relativas ao desenvolvimento da ciência. Mas mesmo uma atitude ou uma postura teórica requer o comprometimento com certas crenças, especialmente crenças metodológicas (cf. sessão 3). Assim, a mera qualificação da NOA como uma atitude não a exime da necessidade de ser argumentada, pois as crenças que compõem uma atitude teórica podem ser tão irrazoáveis quanto qualquer outra crença. Neste ponto, o diagnóstico de Rouse é preciso: "Se ela [a NOA] é uma atitude raciocinada, então a divergência entre seus proponentes e realistas ou anti-realistas não deve cair em petição de princípio. Se ela não é uma atitude raciocinada, então Fine confirma as piores suspeitas de seu oponente" (Rouse 1988, p.296).

\subsection{Abordagem minimalista}

Isto tudo mostra que, se a defesa da NOA depender simplesmente de um princípio meta-filosófico que aponte a NOA como superior às abordagens alternativas (tal como uma preferência por economia teórica, relevância pragmatista, ou anti-globalismo auto-aplicado), então a defesa de Fine se mostra irrazoável, ou ao menos incompleta na medida em que demanda uma defesa anterior e mais clara deste princípio. Felizmente, isto não é tudo o que Fine nos oferece em defesa da NOA, o que nos conduz à abordagem minimalista.

Como já mencionado, a abordagem minimalista não busca silenciar filosofias globais impondo a NOA sobre elas, mas busca obter a NOA como a resultante de não encontrarmos nenhuma filosofia global satisfatória dentre as alternativas no páreo. Com isso, o defensor da NOA assume o ônus teórico de mostrar porque as principais propostas de filosofias globais são filosoficamente insatisfatórias. Isto pode ser sintetizado na seguinte linha argumentativa:

(AEa) Devemos aceitar resultados não-locais (i.e. externos à ciência) somente se tivermos boas razões para fazê-lo. 
(AEb) Não temos boas razões para aceitar as filosofias da ciência não-locais.

(AE) Anti-Essencialismo: Não devemos aceitar resultados não-locais (externos) à ciência.

Primeiramente, (AEa) é introduzida em proximidade com a posição central. Assim, após introduzir a posição central como indicando a aceitabilidade local dos resultados científicos, assume-se uma postura de questionar a razoabilidade de qualquer tentativa de complementar ou revisar esses resultados. E a partir de então, a assunção de (AEb) indica o ônus assumido pela NOA de mostrar que não há filosofias globais satisfatórias dentre as alternativas apresentadas. Qualquer abordagem global (realista ou anti-realista) bem justificada será capaz de falsificar (AEb), e por isso a defesa da NOA requer o apontamento crítico de porque essas abordagens não estão bem justificadas.

Boa parte do trabalho de Fine é dedicado a criticar diretamente as abordagens realistas e anti-realistas (Fine 1984b; 1986a; 1986b). Estas críticas podem ser vistas como uma tentativa de Fine de lidar com o ônus de (AEb) em defesa da NOA. Ainda que as críticas de Fine não se resumam a isto, sua principal estratégia é a de mostrar a existência de circularidades nas defesas tradicionais do realismo e do anti-realismo: o argumento do milagre é formulado como uma inferência abdutiva, ao mesmo tempo em que pretende defender a confiabilidade de inferências abdutivas; a defesa do empirismo construtivo assume um princípio empirista de confirmação que restringe o acesso epistêmico ao observável, mas não há defesa não circular deste princípio ou deste limite epistêmico. ${ }^{7}$ Nesta linha, o movimento geral de Fine para defender $(\mathrm{AEb})$ pode ser sintetizado no seguinte:

(AEba) As razões (argumentos) que temos para aceitar o realismo ou anti-realismo científico globais são circulares em sua estrutura normativa.

(AEbb) Razões circulares em sua estrutura normativa não são boas razões.

$\therefore$ (AEb) Não temos boas razões para aceitar filosofias da ciência (realistas ou antirealistas) não-locais.

Enquanto (AEba) é introduzida pelas mencionadas análises do argumento do milagre e da defesa do anti-realismo feitas por Fine, (AEbb) é assumida implicitamente nas análises de Fine como uma premissa básica, sem argumentação anterior. Embora isto seja compreensível, dado haver uma compreensão ortodoxa de que argumentos circulares sejam problemáticos, esta assunção não defendida de (AEbb) abre uma fraqueza argumentativa, pois tanto as defesas realistas quanto anti-realistas desafiam (AEbb) e são conscientemente circulares. Em ambos os casos, busca-se distinguir entre casos viciosos e casos virtuosos de circularidade na justificação de uma teoria, para então apoiar a defesa realista/anti-realista em um modelo circularmente virtuoso. 
Alguns autores defendem o argumento do milagre (no-miracles argument) formulado explicitamente como uma meta-abdução em favor da confiabilidade de abduções e da metodologia científica (Cf. Boyd 1984), tendo em vista que num cenário de externalismo epistêmico, não há necessidade de justificar certos pressupostos inferenciais fundamentais (Psillos 1999). Para tanto, introduz-se uma distinção entre circularidade de premissas (argumentos que assumem a conclusão como uma de suas premissas) e circularidade de regras (argumentos que concluem a confiabilidade de uma regra de inferência utilizando essa mesma regra), a fim de defender que argumentos com circularidades de regras sejam aceitáveis, e que o argumento do milagre seja aceitável por possuir somente circularidade de regras. Alternativamente, diante de críticas à proposta de inferências de segunda ordem baseadas em circularidade de regras, realistas propuseram também basear o argumento do milagre em uma extensão da aplicabilidade horizontal de inferências abdutivas para uma aceitação de aplicações verticais dessas mesmas regras de inferência (Cf. Kitcher 2001; Silva 2016).

Em contraponto, anti-realistas propõe a utilização de uma dinâmica hermenêutica circular na construção do conceito de observabilidade, onde a ciência determina o que conta como observável ao mesmo tempo em que delimita seu conhecimento ao observável (Van Fraassen 1980, pp.56-9); além disso, essa circularidade na formulação da observabilidade cria uma circularidade epistêmica: "se teorias científicas são o árbitro da observabilidade, então um indivíduo não tem escolha senão usar a teoria da observabilidade aceita por ele como um guia para a observabilidade, e logo como um guia para a adequação empírica, e logo como uma guia para aceitar ou rejeitar aquela mesma teoria" (Monton e Mohler 2017). Diante de tal circularidade, van Fraassen insiste que tal problema seja inevitável e que não haja uma compreensão de observabilidade fundada a priori, do que se segue a plausibilidade de uma concepção empírica (Cf. Monton e Van Fraassen 2003, pp.415-6), além de defender que essa dinâmica circular seja virtuosa na medida em que a determinação do conceito de observabilidade for independente das teorias em que o conceito é usado (Van Fraassen 1980, p.57).

O problema de (AEbb) pode ser visto de modo mais geral, distinguindo entre concepções lineares de evidência, ultimamente baseadas na experiência sensível (propostas fundacionistas); e concepções não-lineares de evidência, segundo as quais crenças possam justificar mutuamente umas às outras (propostas coerentistas ou funderentistas). ${ }^{8} \mathrm{E}$ também entre concepções internistas de evidências, dentre as quais uma argumentação circular pode ser virtuosa unicamente devido a fatores aos quais temos acesso epistêmico; e concepções externistas, onde argumentos circulares podem ser racionais por fatores externos, tal que processos confiáveis de produção de crenças possam ser reflexivamente usados na produção de conhecimento sobre si mesmos (Cf. Sosa 1994). Assumindo que nem realismo nem anti-realismo precisam se com- 
prometer com uma concepção puramente linear e internista de evidência, o trabalho de Fine simplesmente não abarca a possibilidade de evidência não-linear ou externista que torne razoável uma argumentação circular.

Há, portanto, uma miríade de posições sobre qual tipo de argumentação circular é razoável, e há também divergências sobre qual posição (realismo ou anti-realismo) uma dada forma de argumentação circular sustentará. Ao assumir AEbb, Fine toma (de modo dogmático ou circular) como resolvido o que constitui um dos pontos centrais da divergência no debate. E embora as pretensões iniciais de Fine fossem as de reduzir as aspirações epistêmicas do debate através de uma postura filosoficamente deflacionada, mesmo a defesa minimalista e menos contenciosa da NOA acaba dependendo de pressupostos não-consensuais no debate, o que retira da NOA o papel de uma alternativa filosoficamente deflacionada, ao mesmo tempo em que a torna incapaz de resolver efetivamente o impasse tradicional entre realismo e anti-realismo.

\subsection{O Posfácio de 1996}

Na publicação da segunda edição de The Shaky Game, Fine elabora um posfácio (1996) onde comenta algumas das interpretações mencionadas acima. De modo geral, Fine recusa qualquer tentativa de defender a NOA baseando-a em alguma princípio transcendental ou meta-filósofico que prescreva qual atitude preferir, afirmando que isto iria diretamente contra à constituição da NOA (1996, p.176). Ao invés, Fine esclarece:

A NOA é uma atitude, e eu promovo sua adoção. Eu o faço mostrando as fraquezas dos empreendimentos filosóficos rivais, expondo o tipo de bom trabalho que pode ser alcançado ao adotar a atitude da NOA, e propondo um convite: tente-a, você irá gostar! (Fine 1996, p.176).

Esta proposta sintetiza alguns dos pontos discutidos acima. Parte do apelo da NOA está nas fraquezas de posições rivais, conforme sugeria a defesa minimalista. Outra parte está no "bom trabalho" que podemos realizar adotando-a. Fine não é explícito quanto a que trabalho seja esse, mas presumivelmente envolve o fato de a NOA permitir uma postura pró-ciência com uma filosofia minimalista, conforme sugeriam as leituras por parcimônia e por relevância pragmática. E, de um modo parecido com o que sugeria a leitura meta-quietista, Fine evita formular um argumento baseado em princípios que nos constranjam racionalmente, contentando-se com um polido convite.

À primeira vista, isto pode soar como um atestado de que não há um argumento em favor NOA. E, em certo sentido, não há: Fine não está oferecendo nenhum argumento que nos constranja racionalmente na forma de "se você aceita certas premissas, então deve aceitar certa conclusão". Mas a proposta de Fine ainda é interessante por dois pontos. 
Um: a NOA é uma atitude epistêmica. O modo como escolhemos qual atitude adotar é diferente do modo como escolhemos em quais proposições descritivas acreditar. Uma diferença importante é a de que atitudes não possuem valores de verdade, embora possam possuir vantagens (ou desvantagens) relativamente a um conjunto de objetivos alvejados. Neste sentido, a escolha de uma atitude está mais próxima da escolha de uma diretriz ou tática ("policy") do que da escolha de uma crença sobre fatos do mundo. ${ }^{9}$ O que Fine propõe vai precisamente nesta direção. A NOA é comparada com suas rivais em termos de vantagens e desvantagens. Isto não cria um dever racional de aceitá-la, mas pode torná-la mais atraente dependendo dos objetivos e valores epistêmicos que alguém assume.

Em segundo, Fine repele concepções de racionalidade que imponham algoritmicamente quais crenças devemos adotar em um dado contexto, tal como rejeita a distinção entre o normativo e o descritivo (1996, p.178). Faz parte da constituição da NOA que estas categorias também não sejam externamente definidas e impostas à ciência. Ao invés, partimos de nossa prática e partir dela refletimos acerca do que consideramos devido ou razoável. Por isso o que Fine faz é expor razões que talvez tornem a NOA mais atraente para alguns, sem coações.

Isto pode ser suficiente para manter a NOA como uma alternativa possível no debate. Mas parece-me pouco convincente. De modo geral, alguém que se esforce para defender uma posição teórica incompatível com a NOA verá vantagens que motivem sua defesa (o empirismo construtivo de Van Fraassen, formulado em The Scientific Image como uma axiologia da ciência, seria um bom exemplo), e por isso terá de partida um contraponto de razões para não se comover com o convite de Fine. O caráter programático da NOA, portanto, fica prejudicado.

Na próxima seção, proporei uma defesa para reforçar às razões de Fine. Acredito que no posfácio de 1996 Fine negligencie algumas intuições importantes que teve em seus artigos anteriores. Em especial, a proposta de introduzir uma posição central consensual no debate cumpre um papel argumentativo relevante através da estratégia minimalista, mas não é mencionada no convite de Fine. Tentarei trazê-la de volta ao foco.

\section{A primazia da posição central}

Nesta seção, finalmente, apresentarei minha defesa da NOA. Até aqui, vimos primeiro a interpretação doxástica da NOA na qual a posição central constitui uma meio termo doxástico entre realismo e anti-realismo, e vimos como essa leitura esbarra em um problema grave de inteligibilidade: ou adotamos uma concepção referencial de verdade e a posição central se torna realista, ou não adotamos e ela se torna anti-realista. Na sequência, vimos à interpretação da NOA como uma forma de realismo local, dado 
que nessa interpretação a posição central aceita a crença realista (de modo local), e foca-se em questionar o modo com que devemos justificar uma postura realista ou anti-realista. Mais especificamente, a NOA propõe aceitar as crenças realistas/antirealistas de acordo com a própria prática dos cientistas (posição central), e rejeitar revisões filosóficas externas a essa prática (anti-essencialismo). A leitura da NOA como um realismo local esbarrou em duas dificuldades principais. A primeira objeção é a de que, justamente por a NOA ter se tornado uma forma de realismo, a posição central perde seu status de consensualidade e cai em petição de princípio contra o anti-realista. A segunda objeção geral é a de que todas as diferentes formas de defender a premissa anti-essencialista da NOA (compiladas na seção 4) também parecem cair em petição de princípio, uma vez que assumem de antemão algum princípio que exclua a aceitabilidade de abordagens e estilos de raciocínio externos à prática científica. A interpretação da NOA que desenvolverei nesta seção busca esclarecer como a NOA pode lidar com estas duas objeções centrais. Começarei pela proposta geral, para então abordar cada objeção individualmente.

\subsection{A posição central como um modo de aceitação}

Na apresentação da NOA como um realismo local de "andar de baixo", já insisti que o que caracteriza a posição central é a aceitação de um modo ou de uma atitude para decidir se devemos crer numa teoria científica. Isso nos levou a uma compreensão da posição central nos seguintes termos:

[PC3]: Devemos aceitar/rejeitar os resultados científicos de modo local.

Mas mesmo que entendamos PC3 com uma atitude, ela ainda reserva uma ambiguidade perigosa. Quero insistir e deixar transparente que a PC3 não deve ser compreendida como equivalente à PC4:

[PC4]: Ao decidir se devemos ou não crer numa teoria, devemos crer nas teorias aceitas pelos próprios cientistas (e somente nelas).

PC4 também constitui um modo de decidir a questão realista, e também poderia ser apresentada como uma forma de realismo. Mas se definirmos a posição central nestes termos, então inescapavelmente ela cairá em petição de princípio contra o antirealista e contra realistas do andar de cima. Para começar a enfrentar estes problemas, devemos redirecionar a posição central para um outro aspecto da prática científica:

[PC5]: Ao decidir se devemos ou não crer numa teoria, devemos aceitar os valores epistêmicos aceitos na prática científica. 
Tanto PC4 quanto PC5 são atitudes que podemos adotar para resolver a questão realista da verdade de uma teoria. Mas PC4 propõe diretamente que creiamos no que os cientistas creem, e por isso pressupõe que os cientistas sejam uma autoridade confiável para descobrir a veracidade de uma teoria. Em contraste, PC5 consiste na atitude de resolver a questão da verdade de uma teoria como um cientista faria, empregando seus valores epistêmicos e metodologias para avaliar a evidência disponível e para determinar o que podemos inferir a partir dela. ${ }^{10}$ Relembre-se que uma atitude epistêmica é constituída por um modo de engajamento e pela adoção de certos estilos de raciocínio (cf. seção 3), junto com as atitudes proposicionais que eles pressupõem. Assim, quando falo nos valores epistêmicos dos cientistas, refiro-me às suas crenças tácitas acerca de que estilos de raciocínio devem ser aceitos num dado contexto e de como devemos nos engajar epistemicamente com uma dada questão científica (repare que falar em valores, nestes termos, não necessariamente supõe uma distinção categórica entre descrições e normas, ou entre fatos e valores). Por exemplo, em um contexto onde cientistas realizam inferências pela causa mais provável, vemos que o valor explicativo de uma hipótese causal é julgado como um valor epistêmico relevante para autorizar certas inferências (cf. Cartwright 1983).

Compreender PC3 via PC5 não resolve de imediato as duas objeções à NOA, mas nos dará um ponto de partida mais firme para adentrar nelas.

\subsection{Objeção 1: por que a posição central não leva a uma petição de princípio}

No caso da primeira objeção, a formulação da PC em termos de valores epistêmicos ainda não resolve o problema, pois o anti-realista ainda discordará crucialmente da aceitabilidade dos valores epistêmicos de uma comunidade científica quando eles implicarem em uma posição doxástica realista, e defenderá substituí-los por uma contraparte anti-realista destes valores. ${ }^{11}$ Portanto, PC5 continua inaceitável para o anti-realista.

O problema é mitigado se fizermos mais um esclarecimento acerca da posição central. PC5 afirma de modo categórico que devemos aceitar a certos valores, não deixando qualquer abertura para o que anti-realista discorde desses valores sem rejeitar a própria PC5, e disso surge a incompatibilidade entre ambos. Entendo que a proposta de Fine, no entanto, é apenas a de tomarmos esses valores como um ponto de partida para uma investigação aberta, e não necessariamente como o ponto de chegada final em nossas decisões epistêmicas. Uma formulação da PC3 que explicite essa ideia seria a seguinte:

[PC6]: Ao decidir se devemos ou não crer numa teoria, devemos aceitar os valores epistêmicos aceitos na prática científica como possuindo justificação prime facie falível. 
PC6 afirma que, pelo mero fato de certos valores serem aceitos em nossa prática epistêmica, devemos tratá-los inicialmente como justificados. Mas sendo esta justificação de natureza falível, ela só será capaz de efetivar a aceitação posterior desses valores se não houverem derrogadores epistêmicos para tal aceitação, isto é, se não tivermos boas razões para rejeitá-los.

Nestes termos, o anti-realista poderá aceitar a posição central e se manter antirealista (mesmo quando os valores epistêmicos em questão são valores realistas) através da introdução de derrogadores que neutralizem a justificação prima facie que estes valores possuem por constituir a prática científica atual. Com efeito, acredito que esta constitua a forma mais plausível de elaborar (no andar de cima) a própria posição anti-realista: reconhecendo a si mesma como uma posição que revisa os valores epistêmicos de comunidades com viés realista, sem negar ou ignorar a plausibilidade inicial desses valores que os tornou atualmente aceitos.

Além disso, o anti-realista não apenas pode aceitar PC6, como em certo sentido deve, pois rejeitá-la cria um novo ônus teórico: se for rejeitado que (de modo geral) os valores atuais de nossa prática epistêmica possuem uma justificação prima facie interna a ela, então a única forma de evitar o ceticismo radical seria oferecer uma justificação de nossa prática externa a ela, retornando à quimera fundacionista. Ao mesmo tempo, resgatamos a intuição de Fine de encontrar um ponto de partida compartilhado por realistas e anti-realistas científicos, na medida em que ambos rejeitam ao ceticismo radical e atribuem certa razoabilidade a prática epistêmica ordinária e científica.

\subsection{Objeção 2: por que aceitar o anti-essencialismo?}

Mesmo concedendo-se que os valores entrincheirados na prática epistêmica ordinária e científica possuam valor prima facie, ainda resta a questão de como defender o antiessencialismo sem cair em petição de princípio contra os teóricos do andar de cima. Assim, realistas e anti-realistas que assumam filosofias globais ou externas à ciência irão questionar por que não podemos usar estilos de raciocínios externos à prática científica para avaliá-la e criticá-la.

Ao assumimos a posição central conforme vista acima, não proibimos de modo desqualificado o uso de valores epistêmicos externos a uma prática científica (Cf. Fine 1996, p.175). Naturalmente, uma prática científica está sujeita à crítica, e seria dogmatismo exigir que esta crítica se dê apenas nos termos da própria prática. No entanto, a aceitação da posição central estabelece um ponto de partida acerca de como devemos avaliar esta crítica. Assim, suponhamos que (como ocorre na discussão atual) temos disponíveis diferentes posições realistas e anti-realistas no andar de cima, cada uma das quais propõe diferentes revisões nos valores epistêmicos de uma comunidade científica, e cada uma das quais se justifica dentro dos próprios valores 
que propõem. Como avaliamos a legitimidade de cada proposta? A proposta da NOA, incluindo seu caráter anti-essencialista, é a de usar a posição central como ponto de partida para tal avaliação de críticas aos nossos valores epistêmicos atuais. Esta perspectiva de crítica é expressa na estratégia minimalista, onde agora razões se tornarão "boas/más razões" segundo o julgamento dos valores já aceitos pela posição central:

(AEa) Devemos aceitar resultados não-locais (i.e. externos à ciência) somente se tivermos boas razões para fazê-lo.

( $\mathrm{AEb})$ Não temos boas razões para aceitar filosofias da ciência não-locais.

(AE) Anti-Essencialismo: Devemos aceitar somente os resultados científicos locais (ou: não devemos aceitar os resultados científicos não-locais).

O problema anteriormente visto na estratégia minimalista era a acusação de circularidade. Pois haverá uma disputa acerca do que configura uma boa razão. Antirealistas e realistas não-locais certamente julgarão que possuem boas razões para revisar o senso comum científico, tanto quanto estão honestamente convictos de suas posições. Mas o ponto é o de que o julgamento do que conta como uma boa razão deverá partir dos valores epistêmicos internos à prática científica, pois, como vimos acima, há uma prioridade normativa em aceitar os valores epistêmicos já utilizados em nossa prática (ordinária e científica) como justificados prima facie.

Creio que isso mostre como a NOA possa se sair melhor diante dos problemas apresentados na sessão 4. A NOA qualifica a postura de aceitar (ou rejeitar) teorias científicas somente a partir da evidência científica e dos valores epistêmicos já assumidos no senso comum e na ciência. O que justifica a aceitação destes valores é o fato de que ambas as posições do debate precisam aceitá-los como um ponto de partida para seus empreendimentos filosóficos. E que a partir de então, teremos esses valores já aceitos como uma base normativa para avaliar tentativas externas de revisar e criticar nossa prática epistêmica.

Também creio que esta defesa da NOA permita esclarecer uma série de outras objeções erguidas contra Fine: críticos apontam que a NOA dependa de uma distinção demasiado artificial entre evidência local e global, ou entre a imersão na prática científica e a filosofia externa a ela (Abela 1996); também contestam que, diante do problema tradicional do demarcacionismo da ciência, a NOA chega atrasada, uma vez que pressupõe uma preferência pela atitude científica contra outros modos de investigação (cf. Kukla 1994, p.16); ainda, também contestam a coerência da NOA, que protesta contra a filosofia sem sair de dentro dela, de modo que a generalidade do anti-essencialismo para proibir filosofias da ciência parece tornar a NOA exatamente no tipo de abordagem essencialista que a NOA deveria repelir (cf. Rouse 1988, p.298).

Estas críticas se endereçam a uma má concepção da NOA. Pois o cerne da proposta 
de Fine não consiste em dividir abordagens filosóficas em tipos diferentes (globais e locais). Mas sim em tomar como ponto de partida os valores epistêmicos efetivamente usados em nossa vida cognitiva, prática científica inclusa, para então avaliar a abordagens filosóficas a partir desses valores. E não é preciso que a linha entre abordagens locais e globais seja afiada, apenas que, na medida em que uma abordagem filosófica introduz novos valores cognitivos (ou revisa ou complementa antigos valores), ela assume um ônus adicional de justificar este aspecto revisionista de sua abordagem, e assume que este ônus deve ser resolvido através dos valores já aceitos. Assim, o que desqualifica filosofias globais não é meramente seu escopo lógico, mas o fato de essas abordagens serem menos plausíveis e entrincheiradas do que os valores epistêmicos científicos que pretendem revisar ou constringir. Ao menos é o que vemos nas alternativas apresentadas até o momento.

\section{Conclusão}

Neste artigo, analisei qual a melhor maneira de compreender e defender a NOA. Iniciei salientando os dois aspectos principais da NOA, a posição central e o antiessencialismo. Na seção 2, apresentei as tentativas de compreender a NOA em uma formulação doxástica da posição central, que buscam situar a NOA como um meiotermo entre as atitudes de crer que as teorias são verdadeiras (em sentido mínimo referencial), ou descrer nestas teorias. Vimos que, uma vez que o anti-realismo científico também comporta versões agnósticas, não há espaço conceitual para uma NOA como um meio-termo doxástico. Na sessão 3, avancei para a interpretação da NOA como um realismo local que segue a recomendação dos cientistas na aceitação (ou rejeição) da verdade das teorias. Mas, na seção 4 , vimos que as principais formas de defender a NOA nestes moldes ainda encaram dificuldades consideráveis. Em especial, a formulação realista local da posição central, por implicar aceitar a verdade de teorias acreditadas pelos cientistas, aparentemente perderia seu estatuto de posição consensualmente compartilhada no debate; além disso, as tentativas de defender o anti-essencialismo como despachador de teorias filosóficas caíram todas em problemas de circularidade comparáveis aos que Fine atribui ao realismo/anti-realismo tradicionais.

Por fim, apresentei uma via de defesa da NOA destacando seu caráter de atitude epistêmica e baseando-a numa priorização dos valores científicos como um ponto de partida epistêmico. Nesse caso, a formulação realista local da posição central é ligeiramente reformulada, passando a ser compreendida como uma aceitação dos valores epistêmicos aceitos na prática comum e científica como dotados de justificação prima facie falível (i.e. aceitáveis até que se introduza evidência derrogatória). Uma vez que a atribuição de autossuficiência epistêmica à ciência surge do reconhecimento desse 
valor justificatório falível, anti-realistas devem aceitá-la sob pena de tornarem sua posição em um fundacionismo científico. Assim, a posição central retoma seu caráter de consensualidade. Simultaneamente, a introdução desse valor justificatório serve de base para a atitude anti-essencialista sugerida por Fine, agora compreendida como uma atitude crítica de contestar intrusões filosóficas de revisão ou complementação aos valores epistêmicos da ciência. Com isso, a crítica dos valores epistêmicos científicos e do senso comum passa a ser interna, feita por seus próprios valores, ao invés de por teorias filosóficas inteiramente externas a eles. Isso fornece uma base programática para reavaliar os argumentos tradicionais do debate (argumento do milagre, indução pessimista, problema da subdeterminação) a partir da NOA.

\section{Referências}

Abella, P. 1996. Is Less Always More? An Argument Against the Natural Ontological Attitude. The Philosophical Quarterly 46(182): 72-6.

Alspector-Kelly, M. 2003. The NOAer's Dilemma: Constructive Empiricism and the Natural Ontological Attitude. Canadian Journal of Philosophy 33(3): 307-22.

Boyd, R. 1984. On the Current Status of Scientific Realism. In: J. Leplin (ed.) Scientific Realism, pp.41-82. Berkeley: University of California Press.

Brandon, E. P. 1997. California Unnatural: On Fine's Natural Ontological Attitude. The Philosophical Quarterly 47(187): 232-5.

Bueno, O. 1999. O Empirismo Construtivo: uma reformulação e defesa. Campinas: CLE/Unicamp.

Cartwright, N. 1983. How the Laws of Physics Lie. Oxford: Clarendon Press.

Chakravartty, A. 2017. Scientific Realism. In: E. N. Zalta (ed.) The Stanford Encyclopedia of Philosophy. Summer 2017 Edition. https://plato.stanford.edu/archives/sum2017/entries/ scientific-realism/. Access: 01/08/2017.

Crasnow, S. L. 2000. How Natural Can Ontology Be? Philosophy of Science 67(1): 114-32.

Damnjanovic, N.; Stoljar, D. 2014. The Deflationary Theory of Truth. In: E. N. Zalta (ed.) The Stanford Encyclopedia of Philosophy. Fall 2014 Edition. https://plato.stanford.edu/archives/ fall2014/entries/truth-deflationary/. Access: 01/08/2017.

Fine, A. 1984a. The Natural Ontological Attitude. In: J. Leplin (ed.) Scientific Realism, pp.83107. Berkeley: University of California Press.

- 1984b. And Not Antirealism Either. Nous 18(1): 51-65.

- 1986a. The Natural Ontological Attitude. In: The Shaky Game: Einstein, Realism, and the Quantum Theory, pp.112-35. Chicago: Chicago University Press.

- 1986b. Unnatural Attitudes. Mind 95: 149-79.

—. 1991. Piecemeal Realism. Philosophical Studies 61: 79-96. 1993. Fictionalism. Midwest Studies in Philosophy 18(1): 1-18.

- 1996. The Shaky Game: Einstein, Realism and the Quantum Theory. Second Edition. Chicago: The University of Chicago Press.

Ginev, D. 2012. The Natural Ontological Attitude in a Hermeneutic Context. Studia Philosophica Estonica 5(1): 17-43. 
Haack, S. 1993. The Two Faces of Quine's Naturalism. Synthese 94(3): 335-56.

Horwich, P. 1990. Truth. Oxford: Blackwell.

Kitcher, P. 2001. Real Realism: The Galilean Strategy. Philosophical Review 110(2): 151-97.

Kukla, A. 1994. Scientific Realism, Scientific Practice, and the Natural Ontological Attitude. The British Journal for the Philosophy of Science 45(4): 955-75.

Laudan, L. 1984. A confutation of convergent realism. In: J. Leplin (ed.) Scientific realism, pp.218-49. Berkeley: University of California Press.

Leplin, J. 1997. A Novel Defense of Scientific Realism. New York: Oxford University Press.

Maddy, P. 2003. Second Philosophy. Journal of the Indian Council of Philosophical Research 20: 73-106.

Magnus, P. D.; Callender, C. 2004. Realist Ennui and the Base Rate Fallacy. Philosophy of Science 71(3): 320-38.

McMullin, E. 1991. Comment: Selective Anti-Realism. Philosophical Studies 61: 97-108.

Monton, B.; Mohler, C. 2017. Constructive Empiricism. In: E. N. Zalta (ed.) The Stanford Encyclopedia of Philosophy. Summer 2017 Edition. https://plato.stanford.edu/archives/sum2017/ entries/constructive-empiricism/. Access: 01/08/2017.

Monton, B.; van Fraassen, B. 2003. Constructive Empiricism and Modal Nominalism. British Journal for the Philosophy of Science 54: 405-22.

Musgrave, A. 1989. NOA's Ark: Fine for Realism. Philosophical Quarterly 39(157): 383-98.

Niiniluoto, I. 2002. Critical Scientific Realism. New York: Oxford University Press.

Pihlström, S. 1996. Getting Ontologically Natural. International Studies in the Philosophy of Science 10(3): 247-56.

Psillos, S. 1999. Scientific Realism: How Science Tracks Truth. London: Routledge.

Rouse, J. 1988. Arguing for the Natural Ontological Attitude. PSA: Proceedings of the Bienal Meeting of the Philosophy of Science Association 88: 294-301.

Rowbottom, D. P.; Bueno, O. 2011a. How to change: Modes of engagement, rationality, and stance voluntarism. Synthese 178(1): 7-17.

- $-2011 \mathrm{~b}$. Stance and rationality: A perspective. Synthese 178(1): 1-5.

Sankey, H. 2001. Scientific Realism: An Elaboration and a Defence. Theoria 98: 35-54.

Silva, B. M. 2016. O Argumento do Milagre em Prol do Realismo Científico. Dissertação (Mestrado em Filosofia). Universidade Federal do Rio Grande do Sul, Porto Alegre.

Sosa, E. 1994. Philosophic scepticism and epistemic circularity. Proceeding of the Aristotelian Society, Supplementary Volumes 68: 263-90.

Stanford, K. 2006. Exceeding Our Grasp: Science, History, and the Problem of Unconceived Alternatives. Oxford: Oxford University Press.

Teller, P. 2004. What is a Stance? Philosophical Studies 121(2): 159-70.

van Fraassen, B. 1980. The Scientific Image. Oxford: Clarendon Press.

- 1994. Gideon Rosen on Constructive Empiricism. Philosophical Studies 74(2): 17992.

- 2002. The Empirical Stance. New Heaven: Yale University Press.

Wisnewski, J. 2013. Heidegger, Arthur Fine, and the Natural Ontological Attitude. Prolegomena 12(2): 443-58.

Wolff, J. 2019. Naturalistic Quietism or Scientific Realism? Synthese 196(2): 485-98. 


\section{Notas}

${ }^{1}$ A sigla NOA é batizada por Fine e uniformemente aderida pela literatura, creio que aderida a ponto de soar menos como uma sigla do que como um nome próprio. Assim, opto por não traduzir a sigla (a ideia de traduzir a NOA como AON me causa imenso estranhamento).

${ }^{2}$ Tradução minha. Doravante, atente-se que todas as citações estarão traduzidas por mim, enquanto a referência de páginas concerne às obras originais em inglês. Trechos de tradução especialmente problemática terão a citação original replicada.

3“Anti-Realismo" é um gênero com diversas espécies: instrumentalistas, convencionalistas, ficcionalistas, empiristas construtivos, entre outros. Assim, tenha-se em mente que nenhum anti-realista é um anti-realista sem mais, mas sim de alguma espécie específica. No entanto, tomarei aqui um "anti-realista" de modo geral como qualquer defensor da tese de que "não estamos justificados a afirmar que uma teoria científica sobre entidades inobserváveis seja aproximadamente verdadeira". Na terminologia tradicional, isto representa especificamente o anti-realista epistêmico (cf. Chakravartty 2017), cujo principal exemplo é encontrado na obra de van Fraassen (1980).

${ }^{4}$ Posteriormente, Fine (1996 p.184) também afirma adotar uma "não-teoria" da verdade, embora também seja simpático à versão da teoria deflacionista defendida por Paul Horwich (1990). Em ambos os casos, aceita-se o esquema T (' $p$ ' é verdadeira sse $p$ ), e as diferenças surgem acerca do como interpretá-lo. Horwich compreende o Esquema T pela interpretação necessitarista (o esquema $\mathrm{T}$ expressa uma equivalência necessária) e proposicional (onde ' $p$ ' é instanciada por uma proposição). O rótulo 'não-teoria' é tradicionalmente usado para formulações da teoria deflacionista que interpretam o esquema $\mathrm{T}$ de modo analítico (os dois lados do bicondicional do esquema T são analiticamente equivalentes). De todo modo, ambas as versões da teoria deflacionista se comprometem com o esquema $\mathrm{T}$, e logo com o aspecto referencial da verdade, onde a verdade de uma proposição/frase implica na existência dos objetos e/ou propriedades referidos por ela (em contraste, por exemplo, com uma teoria expressivista, cf. Damnjanovic e Stoljar 2014).

${ }^{5}$ É importante notar que nestas mesmas páginas Fine também endossa que as teorias podem ser ditas verdadeiras de um sentido deflacionista de verdade. Isto recolocaria a posição central dentro do escopo de um realismo metafisicamente deflacionado, tal como discutimos acima. Para que esta leitura pragmática da NOA se distancie do realismo, é preciso que dispamos a posição central de qualquer assentimento à verdade referencial das teorias. De um ponto de vista exegético, portanto, essa leitura contraria alegações explícitas feitas por Fine. Ainda assim, é filosoficamente interessante analisá-la como uma forma possível de desenvolver a NOA.

${ }^{6}$ Repare-se, portanto, que há duas distinções presentes aqui: uma entre filosofias do andar de cima e de baixo, marcada pela imersão na atividade científica; e outra entre filosofias locais e globais, marcada como uma questão de escopo. Tal como vejo, a distinção andar de cima/de baixo deve ser vista como a normativamente relevante (isto fica mais claramente exposto em Fine 1996, pp.174-81). Podemos ter abordagens globais ou locais no nível do andar de cima, e ambas serão rejeitadas pela NOA. A NOA permite filosofias locais no andar de baixo. Especulo que, em princípio, uma filosofia global do andar de baixo também seria permitida, mas por definição ela teria de ser algo próximo de uma metaciência.

${ }^{7}$ Uma vez que esta crítica ao argumento do milagre e ao anti-realismo já é tradicional no 
debate, eximo-me de apresentá-la em detalhes. Além disso, curiosamente Fine não desenvolve sua crítica de circularidade à indução pessimista em favor do anti-realismo. Ao invés, ele próprio invoca a indução pessimista em certos momentos ao criticar o realismo, ainda que isto possa ser lido como um mero recurso teórico de redução ao absurdo contra a aceitação de filosofias globais realistas. No entanto, a indução pessimista também poderia ser identificada como circular, uma vez que, para lidar com casos clássicos de regularidades acidentais (tais como o tradicional caso do "verdul", ou da indução de imortalidade baseada em que todos os segundos de minha vida são seguidos por outro segundo de vida), uma inferência indutiva não requer apenas a existência de uma regularidade, mas também a constatação de que essa regularidade é projetável. Assim, também é possível argumentar que a assunção de que a indução pessimista é projetável parece assumir uma rejeição prévia do realismo, uma vez que o realismo bloquearia tal indução.

${ }^{8}$ Susan Haack (1993, pp.344-9) introduz esta distinção para criticar as pretenções deflacionistas do naturalismo quineano (mais especificamente, de sua interpretação mais radical e cientificista). Creio que a distinção sustente uma crítica perfeitamente análoga à NOA.

${ }^{9}$ A analogia entre atitudes ("stances") e diretrizes ("policies") é proposta e aprofundada por Teller (2004). O debate sobre como escolhemos atitudes epistêmicas ganhou força após a publicação de The Empirical Stance de Van Fraassen (2002), e continua bastante em aberto. Acredito que Fine tenha sido um precursor importante deste debate.

${ }^{10}$ Novamente: aqui, não precisamos assumir que exista apenas uma maneira metodológica de abordar a questão como um cientista. Pressupõe-se apenas que existam certas características gerais que separem abordagens minimamente científicas de abordagens externas à ciência.

${ }^{11}$ A expressão mais tradicional é a de falar de um mesmo valor epistêmico como possuindo uma interpretação realista e uma interpretação anti-realista. Assim, por exemplo, apresentamse valores como simplicidade e força empírica como sendo valores relevantes para a escolha de teorias, e questiona-se se estes valores conduzem à verdade (interpretação realista) ou apenas à adequação empírica e outras finalidades pragmáticas (interpretação anti-realista). Aqui, tratarei a ambos como constituindo valores diferentes, ao invés de como constituindo um mesmo valor com diferentes interpretações. Faço-o, tendo em mente que a chamada 'interpretação filosófica' de um valor é na verdade uma parte integrante da atitude epistêmica de uma comunidade (que é o ponto de partida fundamental para a NOA), uma vez que influencia nos juízos de plausibilidade e logo nas inferências feitas dentro dela. Pela perspectiva da NOA, a distinção entre valores epistêmicos e sua interpretação deverá ser feita de dentro da prática científica para que se torne normativamente relevante. Repare-se também que, assim como não existe um meio termo doxástico entre realismo e anti-realismo, também não existe um meio-termo entre uma interpretação realista e uma interpretação anti-realista de certos valores epistêmicos, e portanto um agente epistêmico será forçosamente realista ou anti-realista em seus valores.

\section{Agradecimentos}

Registro minha profunda gratidão ao revisor deste artigo responsável pela leitura paciente e pelos comentários detalhados. Este artigo se beneficiou em diversos pontos com estes comentários, embora algumas questões tenham sido negligenciadas devido ao tamanho já extenso do artigo. Este artigo foi produzido durante período de pesquisa financiado pela CAPES. 